\title{
A glance at acute pancreatitis (AP)
}

\begin{abstract}
Pancreatitis is the necroinflammation of the pancreatic tissue based pathologically on autodigestion, and deranged microvasculature that finally result in necrosis and later be complicated by bacterial infection. Pancreatitis takes place mainly due to calcular gall bladder, alcohol consumption, hypercholesterolaemia, immunologic, and blunt trauma, however it may be idiopathic. Pancreatitis varies in clinical severity i.e mild-severe, and presentation i.e acute -chronic. Many scoring systems have been proposed in assessing the severity of pancreatitis. Diagnosis must be considered in clinically suspected cases, and confirmed biochemically and radiologically. Treatment is directed to treating the cause, supportive measures e.g fluids, and managing complications.
\end{abstract}

Volume 7 Issue 2 - 2017

\author{
Raghda Marzaban \\ Associate Professor of Infectious Diseases \& Endemic \\ Hepatogasroenterology, Cairo University, Egypt
}

Correspondence: Raghda Marzaban, Associate Professor of Infectious Diseases \& Endemic Hepatogastroenterology, Faculty of Medicine, Cairo University, Egypt, Email egymarz@yahoo.com

Received: April 30, 2017| Published: July 19, 2017

\section{Introduction}

Acute pancreatitis (AP) is one of the commonest reasons for hospitalized cases due to gastrointestinal disease. ${ }^{1}$ It is a severe disease affecting millions of people worldwide. Although supportive and critical care are advancing, no targeted pharmacologic treatment is used specifically to treat AP. ${ }^{2}$

A global epidemiologic study applied in 188 countries documented the rising incidence of pancreatitis; 4-8\% before 1998, 14.9\% 19982013, and overall $16 \%{ }^{3}$ A British study showed significant increase of AP from 27.6 per 100000 in 1999 to 36.4 in 2010 (average annual increase $=2.7 \%$ per year), particularly among young women aged $<35$ years, during the Christmas and New Year weeks in alcoholic aetiology, and socially deprived (1.9 times higher). ${ }^{4}$

An American study proved that AP affects both genders comparably, and generally increases with age. It also found its higher incidence among black races more than the others. Regarding the aetiolgy, gallstones are the most common cause AP, and conversely, early cholecystectomy eliminates the risk of recurrence. ${ }^{5}$ Smoking is an independent risk factor for AP [5,6], including the recurrence, incidence in young age, and regardless the aetiology. ${ }^{6}$

Common aetiologies of AP are summarized as follows, provided that gallstones and alcoholism constitute $75 \%$ od causes:

i. Obstructive (Gallstones, Biliary sludge and microlithiasis, Tumors, helminthes), and functional (Sphincter of Oddi Dysfunction)

ii. Alcohol, toxins, drugs

iii. Metabolic disorders (Hypertriglyceridemia, Hypercalcemia)

iv. Iatrogenic e.g Post ERCP

v. Trauma

vi. Infections

vii. Vascular-Ischemia

viii. Hereditary

ix. Congenital anomalies (Pancreas Divisum, annular pancreas, choledocele, duodenal diverticula) $)^{7}$ Idiopathic $(10-20 \%)^{8}$

x. Miscellaneous (autoimmune pancreatitis, ${ }^{9}$ Crohn's disease, ${ }^{10}$ Celiac disease $)^{11}$

\section{Pathology}

It can be divided into four different pathogenologic categories: i) Ductular where intraductal pressure and permeability increase with premature enzyme activation, ii) Acinar in which autoactivation of pancreatic enzymes take place after misdirected basolateral secretion into the interstitium of the pancreas and/or by localization of lysosomes and proenzyme-rich zymogen granules inside the acinar cell, iii) Mixed ductular-acinar which is a combination of increased intraductal pressure, duct permeability and a potential direct toxic effect, and iv) Altered pancreatic microcirculation which plays a key role in the progression of edematous to necrotizing pancreatitis. Haemoconcentration and hypercoagulability, impaired perfusion by vasospasms of capillary flow by direct endothelial injury and edema, and of venous outflow by thrombosis, leukocyte endothelial direct toxic injury by activated enzymes, kinins and other mediators ${ }^{12}$ altogether play in the pathogenesis of AP.

Activated enzymes and oxygen free radicals injure the acinar cell and cause a release of cytokines and vasoactive mediators, attract inflammatory cells and activate the vascular endothelium and the adhesion molecules. The disturbance of the pancreatic microcirculation induces a progression from edematous to necrotizing pancreatitis. ${ }^{13}$

Systemic inflammatory response syndrome (SIRS), secondary to cytokine release from the initial pancreatic parenchymal injury, is the main cause of early complications within the first 14 days. ${ }^{14}$ Moreover, intestinal dysfunction is thought to be related to the SIRS via intestinal ischaemia-reperfusion injury, and stimulation of local fluid collection in the retroperitoneal space and abdominal cavity. ${ }^{15}$ Synergistic element mediated by the intestinal hormones i.e motilin, vasoactive intestinal peptide, and cholecystokinin are incorporated as well. ${ }^{16}$

\section{Clinical picture}

Abdominal pain is the cardinal symptom that occurs in about $95 \%$ of cases. It is a deep dull aching pain which takes place typically in the upper abdomen radiating backwards in a band/ belt-like pattern, but it may be more localized to the right upper quadrant, epigastric area, or, less commonly in the left upper quadrant. Also, it charctaristically occurs acutely, without a prodrome, and progresses soon afterwards, and may last for days. Eating or drinking particularly alcohol exacerbates the pain. In severe pain, patient attains the faetal position (knee-to-chest) to reduce its intensity. On examination, signs depend 
on the severity of pain. Mild cases present with mild abdominal tenderness, while severe ones present guarding as well, but rebound tenderness is unusual. Ileus, signify the spread of the inflammation to the adjacent transverse colon. Tachycardia and mild hypotension may result from hypovolemia from sequestration of fluid in the pancreatic bed. About $60 \%$ of patients develop low-grade pyrexia from peripancreatic inflammation without evident infection. ${ }^{17}$

The evaluation of AP severity has been firstly defined by Atlanta Classification which was a clinically based classification system as mild and severe forms in an International Symposium on AP, ${ }^{18}$ that

Table I Severity of AP. ${ }^{23}$

\begin{tabular}{|c|c|c|}
\hline Severity of AP & Atlanta criteria (1993) & Atlanta revision $(20 \mid 3)$ \\
\hline Mild & $\begin{array}{l}\text { Absence of organ failure } \\
\text { Absence of local complications }\end{array}$ & \\
\hline $\begin{array}{l}\text { Moderate } \\
\text { (in revised Atlanta 2013) }\end{array}$ & & $\begin{array}{l}\text { I. Local complications AND/OR } \\
\text { 2. Transient organ failure }(<48 \mathrm{~h})\end{array}$ \\
\hline Severe & 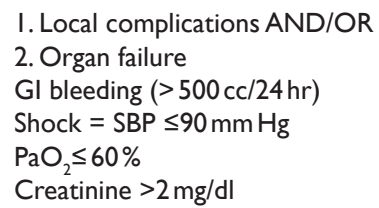 & Persistent organ failure $>48 \mathrm{~h}$ \\
\hline
\end{tabular}

was revised 20 years later regarding severity grades as mild, moderate and severe, and definition including duration of complications. ${ }^{19}$

According to the timing of complications, AP has 2 distinct phases; early ( $\leq 1$ week) characterized by the SIRS and/or organ failure; and late ( $>1$ week), characterized by local complications. ${ }^{20}$ Bacterial infection of pancreatic necrotic tissue is a frequent (30-70\%) complication and is the leading cause of deaths in severe cases. ${ }^{21}$ Pancreatic necrosis is defined as nonviable pancreatic tissue, whether focal or diffuse, $>3 \mathrm{~cm}$ in size or $>30 \%$ of the pancreas. ${ }^{22}$ Severity of AP is summarized in Table $1 .^{23}$

\section{$\mathrm{Gl}$, Gastrointestinal; $\mathrm{PaO}_{2}$, arterial oxygen saturation}

Several scoring systems have been proposed in evaluating the severity of AP resulting in mortality; a) Ranson et al. ${ }^{24}$ based on 11 objective variables assessed on admission and at $48 \mathrm{hrs}$ later, that was modified by AbuEshy et al. ${ }^{25}$ who proved 4 of them i.e serum glucose value of $\geq 160 \mathrm{mg} / \mathrm{dl}$, blood urea nitrogen (BUN) rise of $\geq 35 \mathrm{mg} / \mathrm{dl}$, Blood pressure $\leq 55 \mathrm{~mm} \mathrm{Hg}$, and serum calcium value of $<8 \mathrm{mg} / \mathrm{dl}$ (the most significant one) related to complications. b) Acute Physiology and Chronic Health Evaluation (APACHE)- $\alpha$ scores were applied since $1970 \mathrm{~s} .{ }^{26} \mathrm{c}$ ) A new prognostic scoring system, the Bedside Index for Severity in AP (BISAP), has recently been proposed as an accurate and simple method for early identification of patients at risk of inhospital mortality ${ }^{27}$ based on 5 parameters i.e BUN $>25 \mathrm{mg} / \mathrm{dl}$, altered conscious level, SIRS, age $>60$ years, and pleural effusion.

However, those scoring systems showed rather similar predictive accuracy for severity of AP. ${ }^{28}$ The majority ( $80 \%$ ) of acute pancreatitis cases are of mild picture, and without complications, ${ }^{29}$ and generally resolve themselves spontaneously within few days, without the need for specific treatment. ${ }^{30}$

Early complications i.e within 2 weeks of the attack are biliary obstruction, haemorrhage, extensive sterile necrosis, infection of the necrosis, peritonitis, multi-organ failure, deterioration, Wirsung rupture. ${ }^{31}$ Variables found to be related to systemic complications were the APACHE II score as well as Sequential Organ Failure Assessment (SOFA) and Marshall scores ${ }^{32}$ greater than 3 . The variables related to mortality were SOFA score $>3$, leukocytic count $>19,000 \mathrm{~mm}^{-3}$, CRP $>19.5 \mathrm{mg} / \mathrm{dL}$ and length of hospital stay were related to necrotizing pancreatitis. $^{33}$

\section{Prognosis}

The overall mortality rate of acute pancreatitis ranges from $4.8 \%{ }^{34}$ - 9.2\%. ${ }^{14}$ Its range was reported $10-24 \%{ }^{35} 7.7 \%{ }^{33}-13.5 \%$ of severe cases, and early deaths i.e $\leq 14$ days occur in the half of patients $(55 \%)$ due to multi-organ system failure (MOF), while later deaths occur due to complications secondary to the infection of pancreatic necrosis which may be secondarily result in multi-organ system failure..$^{34}$ Duration and timing of organ failure is the limiting factor in determining outcome such that resolution within 48 hours suggests a good prognosis while its persistence is a marker for subsequent death or local complications. ${ }^{36}$

\section{Diagnosis}

AP is diagnosed by at least the first 2 of 3 features (4): a) abdominal pain (typically epigastric pain radiating to the back), b) serum amylase and lipase levels $\geq 3$ times normal, and (c) characteristic findings on computed tomography (CT), magnetic resonance imaging (MRI). ${ }^{19}$ Amylase is considered the elementary test used in diagnosing AP as it rises rapidly within the first 12 hours after the onset of symptoms and returns to normal within 3-5 days. ${ }^{37}$ However, it may be normal in 19$32 \%$ of cases. Conversely, it may be elevated in other intraabdominal and salivary inflammatory conditions, and also in renal impairment or macroamylasaemia. ${ }^{39}$

On the other hand serum lipase activity remains increased for up to $8-4$ days, thus is higher in sensitivity, and it may reach $>4$ times that its upper normal limit. Moreover, less influenced by pancreatic insufficiency. ${ }^{40}$ The actim Pancreatitis strip testrecorded 93\% sensitivity, $92 \%$ specificity, and $99 \%$ negative predictive value of. It is superior to serum lipase (sensitivity $79 \%$ and specificity $88 \%$ ). ${ }^{41}$

Novel serum markers procalcitonin and Interleukin 6 (IL-6) allow earlier prediction (12 -24 hours after admission). Serum alanine aminotransferase (ALT) $>150 \mathrm{IU} / 1$ and jaundice suggest a gallstone aetiology requiring ERCP. For obscure aetiologies, serum calcium and triglycerides should be measured. Genetic polymorphisms may have an important role in "idiopathic" acute recurrent pancreatitis. ${ }^{42}$

Imaging is done when the blood tests are not elevated and the diagnosis is questionable. ${ }^{43}$ It is recommended to confirm the clinical diagnosis, diagnose its cause, exclude alternative causes of abdominal pain, and grade the extent and severity. ${ }^{44}$ 
US is the basic imaging modality in most centers to confirm the diagnosis of AP and ruling out of other causes of acute abdomen, ${ }^{45}$ yet, sometimes of limited value. ${ }^{44}$ US shows focally or diffusely enlarged hypoechoic pancreatic gland. Ill defined anechoic areas signify peripancreatic free fluid collections, and internal echoes/ septations suggest hemorrhage or a superimposed infection. ${ }^{46}$

CT is considered superior as it enables staging the severity of AP, while MRI characterizes pancreatic and peripancreatic fluid collections and assessing an abnormal or disconnected pancreatic duct, particularly in iodine allergic patients.$^{45}$ Balthazar CT severity index $(\mathrm{CTSI})^{47}$ is considered a reliable imaging scoring system as it stratified pancreatitis severity and correlated pancreatic necrosis with parenchymal affection including fluid collection.

\section{Treatment}

Strategy of treatment plan is summarized in Table $2 .^{2}$ The most effective intervention for acute pancreatitis is early aggressive fluid resuscitation as it provides adequate pancreatice perfusion microcirculation, and maintains its intravascular volume. ${ }^{22}$ Antibiotics should be discontinued whenever blood and other cultures are negative and no source of infection is identified. ${ }^{23}$
Enteral nutrition is beneficial as it reduces infectious complications, MOF, and mortality. Regarding the route of enteral feeling, nasogastric tube is equally as effective as nasojejunal feeding, while regarding the timing of enteral nutritional support, relatively early administration within $48-72 \mathrm{~h}$ of hospital admission is recommended. ${ }^{48}$ Only, in mild AP with resolved abdominal pain, and with neither nausea nor vomiting, oral low-fat solid diet can be started immediately. ${ }^{23}$

However, minimally invasive approaches to pancreatic necrosectomy including laproscopic surgery, percutaneous, radiologic catheter drainage or debridement, video-assisted or small incisionbased left retroperitoneal debridement, are increasingly becoming the standard of care. ${ }^{49}$ Percutaneous drainage without necrosectomy may be the most frequently used minimally invasive method for managing fl uid collections complicating necrotizing AP. Sometimes these modalities can be combined at the same time or sequentially. ${ }^{50}$ Angiography is used to diagnose some complications like pseudoaneysm due to the lytic effect on vascular wall by the activated pancreatic enzymes or selective embolization to control bleeding. ${ }^{51}$

Finally, an integrated multidisciplinary approach is required in patients with severe pancreatitis e.g gastroenterologists, radiologists, intensivists, and surgeons. Identification of the cause and its proper treatment is very crucial. ${ }^{52}$

Table 2 Strategy of treatment plan . ${ }^{2}$

\begin{tabular}{|c|c|}
\hline \multicolumn{2}{|c|}{ Intervention recommendation } \\
\hline Antibiotics & $\begin{array}{l}\text { Not recommended unless there is a documented infection } \\
\text { No prophylaxis for necrotizing acute pancreatitis }\end{array}$ \\
\hline Feeding & $\begin{array}{l}\text { Attempt enteric feeding within the first } 72 \text { hours of admission if tolerated (may be supplemented with oral } \\
\text { low-fat diet) }\end{array}$ \\
\hline Pharmacologic strategies & $\begin{array}{l}\text { No current targeted pharmacologic therapies recommended } \\
\text { Rectal indomethacin } 100 \mathrm{mg} \text { for post-procedure prophylaxis in } \\
\text { those at high risk for post ERCP pancreatitis }\end{array}$ \\
\hline
\end{tabular}

\section{Conclusion}

AP is a serious medical condition that is potentially lethal. Its diagnosis has to be considered whenever any of the aetiologies exist with its classical presentation.

\section{Recommendation}

Proper assessment and evaluation of AP with prompt intervention to avoid complications and mortality.

\section{Acknowledgments}

None.

\section{Conflicts of interest}

The authors declare there are no conflicts of interest related to the article.

\section{Funding}

None.

\section{References}

1. Forsmark CE, Swaroop Vege S, Wilcox CM. Acute pancreatitis. N Engl J Med Massachusetts Medical Society. 2016.
2. Janisch N, Gardner T. Recent advances in managing acute pancreatitis. F1000Research. 2015;18: 4.

3. Vos T, Barber RM, Bell B, et al. Global, regional, and national incidence, prevalence, and years lived with disability for 301 acute and chronic diseases and injuries in 188 countries, 1990-2013: a systematic analysis for the Global Burden of Disease Study 2013. Lancet. 2015;386(9995):743-800.

4. Roberts SE, Akbari A, Thorne K, et al. The incidence of acute pancreatitis: impact of social deprivation, alcohol consumption, seasonal and demographic factors. Aliment Pharmacol Ther. 2013;38(5):539548 .

5. Yadav D, Lowenfels AB. The epidemiology of pancreatitis and pancreatic cancer. Gastroenterology. NIH Public Access. 2013;144(6):12521261.

6. Munigala S, Conwell DL, Gelrud A, et al. Heavy Smoking Is Associated With Lower Age at First Episode of Acute Pancreatitis and a Higher Risk of Recurrence. Pancreas. 2015;44(6):876-881.

7. Ratia Gimenez T, Calvo AG, Vicent JG. Etiology of acute pancreatitis. Cent Eur J Med. 2014;9(4):530-542.

8. UK Working Party on Acute Pancreatitis. UK guidelines for the management of acute pancreatitis. Gut. 2005;54:1-9.

9. Krasinskas A, Raina A, Khalid A. Autoimmune pancreatitis. Gastroenterol Clin North Am. 2007;36:239-257. 
10. Noomen CG, Veenendaal RA, Verspaget HW. Gastroduodenal Crohn's disease and pancreatitis. Gastroenterol Hepatol (N Y). 2008;4(7):496498.

11. Sadr-Azodi O, Sanders DS, Murray JA, et al. Patients with celiac disease have an increased risk for pancreatitis. Clin Gastroenterol Hepatol. 2012;10(10):1136.e3-1142.e3.

12. Schmidt J, Klar E. Etiology and pathophysiology of acute pancreatitis. Ther Umsch. 1996;53(5):322-332.

13. Klar E, Werner J. New pathophysiologic knowledge about acute pancreatitis. Chirurg. 2000;71(3):253-264.

14. Toh SK, Phillips S, Johnson CD. A prospective audit against national standards of the presentation and management of acute pancreatitis in the South of England. Gut. 2000;46(2):239-243.

15. Seerden T, De Winter B, Van Den Bossche R, et al. Regional differences in gastrointestinal motility disturbances during acute necrotising pancreatitis. Neurogastroenterol Motil . 2005;17(5):671-679.

16. Wang X, Gong Z, Wu K, et al. Gastrointestinal dysmotility in patients with acute pancreatitis. J Gastroenterol Hepatol. 2003;18(1):57-62.

17. Cappell MS. Acute Pancreatitis: Etiology, Clinical Presentation, Diagnosis, and Therapy. Med Clin N Am. 2008;92(4):889-923.

18. Bradley EL. A clinically based classification system for acute pancreatitis. Summary of the International Symposium on Acute Pancreatitis, Atlanta, Ga, September 11 through 13, 1992. Arch Surg. 1993;128(5):586-1590

19. Sarr M, Banks P, Bollen T. Revision of the Atlanta classification of acute pancreatitis. Acute Pancreatitis Classification Workgroup. 2008;262(3).

20. Busquets J, Fabregat J, Pelaez N, et al. Factors influencing mortality in patients undergoing surgery for acute pancreatitis. Pancreas. 2014;43(6):977.

21. Isenmann R, Beger HG. Natural history of acute pancreatitis and the role of infection. Baillieres. Best Pract Res Clin Gastroenterol. 13(2):291301.

22. Banks P, Freeman M. Practice Parameters Committee of the American College of Gastroenterology: Practice guidelines in acute pancreatitis. Am J Gastroenterol. 2006;101(10):2379-2400.

23. Tenner S, Baillie J, DeWitt J, et al. American College of Gastroenterology Guideline: Management of Acute Pancreatitis. Am J Gastroenterol. 2013;108(9):1400-1415.

24. Ranson J, Rifkind K, Roses D, et al. Objective early identification of severe acute pancreatitis. Am J Gastroenterol. 1974;61(6): 443-451.

25. Abu-Eshy SA, Abolfotouh MA, Nawar E, et al. Ranson's criteria for acute pancreatitis in high altitude: do they need to be modified? Saudi J Gastroenterol. 2008;14(1):20-23.

26. Larvin M, McMahon MJ. APACHE-II score for assessment and monitoring of acute pancreatitis. Lancet. 1989;2(8656):201-205.

27. $\mathrm{Wu} \mathrm{BU}$, Johannes RS, Sun $\mathrm{X}$, et al.The early prediction of mortality in acute pancreatitis: a large population-based study. Gut 2008;57(12):1698-1703.

28. Cho JH, Kim TN, Chung HH, et al. Comparison of scoring systems in predicting the severity of acute pancreatitis. World $J$ Gastroenterol. 2015;21(8):2387-2394

29. Frossard J, Steer M, Pastor C. Acute pancreatitis. Lancet. 2008;371:143152.

30. Clancy T, Benoit E, Ashley S. Current Management of Acute Pancreatitis. J Gastrointest Surg. 2005;9:440-452.
31. Bassi C, Falconi M, Butturini G, et al. Surgical treatment: evidencebased and problem-oriented. early complications of severe acute pancreatitis. Zuckschwerdt, Munich, Germany. 2001.

32. Carioca AL, Jozala DR, Bem LO de, et al. Severity assessment of acute pancreatitis: applying Marshall scoring system. Rev Col Bras Cir. 2015;42(5):325-327.

33. De Campos T, Cerqueira C, Kuryura L, et al. Morbimortality Indicators in Severe Acute Pancreatitis. JOP. J Pancreas. 2008;9(6):690-697.

34. Carnovale A, Rabitti P, Manes G, et al. Mortality in Acute Pancreatitis: Is It an Early or a Late Event?. JOP J Pancreas. 2005;6(5):438-444.

35. Lund H, Tønnesen H, Tønnesen MH, et al. Long-term recurrence and death rates after acute pancreatitis. Scand $J$ Gastroenterol. 2006;41(2):234-238

36. Johnson C, Abu-Hilal M. Pancreas. Persistent organ failure during the first week as a marker of fatal outcome in acute pancreatitis. Gut 2004;53(9):1340-1344.

37. Smotkin J, Tenner S. Laboratory Diagnostic Tests in Acute Pancreatitis. $J$ Clin Gastroenterol. 2002;34(4):459-462.

38. Spechler SJ, Dalton JW, Robbins AH, et al.Prevalence of normal serum amylase levels in patients with acute alcoholic pancreatitis. Dig Dis Sci. $1983 ; 28(10): 865-869$.

39. Keim V, Teich N, Fiedler F, et al. A comparison of lipase and amylase in the diagnosis of acute pancreatitis in patients with abdominal pain. Pancreas. 1998;16(1):45-49.

40. Tietz NW, Shuey DF. Lipase in serum--the elusive enzyme: an overview. Clin Chem. 1993;39(5):746-756.

41. Kylänpää-Bäck ML, Kemppainen E, Puolakkainen P, et al. Comparison of urine trypsinogen-2 test strip with serum lipase in the diagnosis of acute pancreatitis. Hepatogastroenterology. 2002;49(46):1130-1134.

42. Matull WR, Pereira SP, O’Donohue J. Biochemical markers of acute pancreatitis. J Clin Pathol. 2006;59(4):340-344.

43. Complementary Pancreatitis Therapies - The National Pancreas Foundation. 20th anniverasary.

44. O’Connor OJ, McWilliams S, Maher MM. Imaging of Acute Pancreatitis. Am J Roentgenol. American Roentgen Ray Society. 2011;197(2):W221W225.

45. Türkvatan A, Erden A, Türkoğlu MA, et al. Imaging of acute pancreatitis and its complications. Part 1: Acute pancreatitis. Diagn Interv Imaging. 2015;96(2):151-160.

46. Jeffrey RB. Sonography in acute pancreatitis. Radiol Clin North Am. 1989;27(1):5-17.

47. Balthazar EJ. Acute pancreatitis: assessment of severity with clinical and ct evaluation. Radiology. 2002;223(3):603-613.

48. Oláh A, Romics L. Enteral nutrition in acute pancreatitis: a review of the current evidence. World J Gastroenterol. 2014;20(43): 16123-16131.

49. Freeman ML, Werner J, van Santvoort HC, et al. International Multidisciplinary Panel of Speakers and Moderators. Interventions for Necrotizing Pancreatitis. Pancreas. 2012;41(8):1176-1194.

50. van Santvoort HC, Besselink MG, Bakker OJ, et al. Dutch Pancreatitis Study Group. A Step-up Approach or Open Necrosectomy for Necrotizing Pancreatitis. N Engl J Med. 2010;362(16):1491-1502.

51. Boudghene F, L"Hermine C, Bigot J. Arterial complications of pancreatitis: diagnostic and therapeutic aspects in 104 cases. Radiol, $J$ Vasc Interv. 1993;4(4):551-558.

52. Vanwoerkom R, Adler DG. Acute pancreatitis: review and clinical update. Hopsital physician, 20009. pp. 9. 